\title{
¿Un Tribunal Constitucional Internacional? Una visión problemática
}

\author{
Miguel Ayuso ${ }^{1}$
}

\begin{abstract}
Resumen: La construcción del constitucionalismo plantea problemas relativos al Estado que se constituye, al poder constituyente a través del que se crea una Constitución y a la interpretación de ésta por un órgano al que se atribuye de modo eminente la interpretación y aplicación de la Constitución. Cuando trasladamos estos problemas al nivel internacional, lejos de facilitarse su solución, se hace más ardua. En particular en un tiempo en el que la crisis del constitucionalismo ha llevado a algunos a hablar de neo-constitucionalismo y a otros - como el autor- de post-constitucionalismo.

Palabras Clave: Constitución - Constitucionalismo - Tribunal Constitucional - Poder constituyente Estado - Globalización - Neo-constitucionalismo - Post-constitucionalismo.
\end{abstract}

Abstract: From constitutionalism arise some problems concerning the State who is being constituted, the constituent power through Constitution is created and how constitutional Courts interpret and aplicate Constitution. When these problems are transferred to an international level, solution does not become easier but on the contrary more difficult. Particularly in our days, when crisis in constitutionalism is carrying some people to talk of neo-constitutionalism and others -like the author- of postconstitutionalism.

Keywords: Constitution - Constitutionalism - Constitutional jurisdiction - Constitutional Court Constituent power - State - Globalisation - Neo-constitutionalism - Post-constitutionalism

\section{Incipit}

La jurisdicción constitucional va referida a la interpretación y aplicación de la Constitución, que a su vez remite a la existencia de un Estado que es el que con la misma «se constituye» por medio del ejercicio del poder constituyente (puro o constituido). Hay, pues, cinco elementos estrechamente entrelazados: el Tribunal Constitucional, la hermenéutica constitucional, la Constitución, el poder constituyente y el Estado que se constituye.

\section{El Tribunal Constitucional y la Constitución del Estado}

Es sabido, en primer lugar, que la jurisdicción constitucional, en el modelo más extendido, se ha encarnado desde el punto de vista organizatorio en un órgano especializado que se denomina Corte o Tribunal Constitucional. Que no excluye una cierta intervención de los órganos que administran justicia, si bien se reserva el monopolio de la declaración de la inconstitucionalidad de las leyes. Frente al modelo

\footnotetext{
${ }^{1}$ Universidad Pontificia Comillas de Madrid.
} 
originario de los Estados Unidos de América, donde funcionalmente queda residenciada en los tribunales ordinarios ${ }^{2}$.

Un segundo conjunto de problemas toca precisamente a la interpretación y aplicación de la Constitución, en particular por el Tribunal Constitucional. Respecto de lo que es también común distinguir dos modelos aparentemente opuestos aunque finalmente no tan distantes: el de Hans Kelsen y el Carl Schmitt. Si estamos con Kelsen, nos desenvolvemos en el seno de la «geometría legal» ${ }^{3}$. Donde los principios operan como axiomas a partir de los cuales se deduce. En efecto, las Constituciones, que comienzan habitualmente por un preámbulo, encierran en un primer lugar los llamados principios fundamentales, a partir de los que debe leerse el resto del articulado. Los principios fundamentales representan, pues, los postulados de los que debe traer causa la interpretación de la Constitución. Se trata, además, de un proceso deductivo vinculante, en el que a lo sumo caben tipos abiertos, pero no interpretaciones abiertas. El positivismo kelseniano se resuelve, así, en un legalismo constitucional que no ha dejado de poner problemas tanto al legislador como a los tribunales constitucionales. Si, por el contrario, nos situamos tras Schmitt, el preámbulo y los principios fundamentales pasan a ser de contenido variable y asumen un significado diferente según el momento histórico. Y aunque la Constitución permanezca idéntica en su letra, es objeto de mutaciones sustanciales respecto del contenido de los derechos, convirtiéndose entonces la interpretación en constitutiva de los principios. Pero no se trata de modelos inmóviles. Para empezar, el kelseniano ha conocido una evolución hacia los tipos abiertos, mientras que el schmittiano ha debido enfrentarse con la evidencia de las interpretaciones que chocan con las precedentes. Surge de ahí la pregunta central: ¿son las sentencias de los tribunales constitucionales meros actos interpretativos de la Constitución que deben permanecer fieles a su tenor en el momento de la aprobación o son actos que innovan la Constitución a través de su interpretación? ${ }^{4}$ Cuando los tribunales constitucionales trascienden la interpretación para ingresar en la novación de la Constitución, exceden por ello del simple poder jurídico, aun en los términos más abiertos que quiera pensarse, para integrar un poder político ejercitado por medio de la hermenéutica ${ }^{5}$.

Resulta claro, en tercer lugar, que lo implicado en lo anterior es la propia noción de Constitución. Que no se suele indagar teoréticamente sino a lo sumo teóricamente, esto es, sociológicamente ${ }^{6}$. También aquí es dado hallar una notable diferencia entre el sistema anglosajón y el continental ${ }^{7}$. La Constitución (incluso la escrita según el modelo europeo continental) «puede resultar útil como conjunto de leyes constitucionales, esto es, como conjunto de normas de grado superior a las

\footnotetext{
2 Es clásica la explicación de la formación del modelo estadounidense de MCILWAIN, C. H. Constitutionalism. Ancient and modern. Edición revisada. Ithaca: Cornell University Press, 1947. En lo que respecta al modelo europeo puede verse HÄBERLE, $P$ (ed.). Verfassungsgerichtsbarkeit. Darmstadt: Wissenschaftliche Buchgesellschaft, 1976. Una visión panorámica clásica, finalmente, en FAVOREU, L. Les cours constitutionelles. Paris: PUF, 1986.

${ }^{3}$ De esta expresión, de impronta viquiana, si no me equivoco, hizo uno de los ejes de su obra el profesor Francesco Gentile, del que puede verse en especial Ordinamento giuridico fra virtualità e realtà. $3^{\mathrm{a}}$ ed. Padova: CEDAM, 2005.

${ }^{4}$ En sede estadounidense, como es sabido, el tema ha conocido éxito tan notable como polémico bajo la rúbrica del «originalismo» (aplicable a Antonin Scalia y Robert Bork) y sus contradictores (Dworking, entre muchos). Cfr., para una crítica aguda, FERRARA, C. A. Las «uniones del mismo sexo» y el problema del positivismo legal. Una perspectiva desde los Estados Unidos. In AYUSO, M. (ed.): Estado, ley y conciencia. Madrid: Marcial Pons, 2010, p. 89-127.

5 CASTELlANO, D. Costituzione e costituzionalismo. Napoli: Edizioni Scientifiche Italiane, 2013, capítulo IV.

${ }^{6}$ Para la distinción entre teorético y teórico, véase CASTELLANO, D. La naturaleza de la política. Barcelona: Scire, 2006, p. 11-18.

${ }^{7}$ Véase PEREIRA MENAUT, A.C. Rule of law o Estado de derecho. Madrid: Marcial Pons, 2003.
} 
ordinarias, a fin de tutelar el orden natural de la comunidad política (orden que es "dado", no "creado") sobre todo en las circunstancias sociales y en los momentos históricos en que hay mayor necesidad de controlar apetitos y pasiones de los ciudadanos o de las partes de la comunidad política. Debe rechazarse, así, la Constitución como condición del ordenamiento jurídico y, sobre todo, del derecho, aunque se postule a veces de manera distinta a la teoría de la soberanía. La política auténtica, en efecto, es realeza, no poder soberano» ${ }^{8}$.

Tal consideración, a continuación, implica necesariamente una revisión de la doctrina del poder constituyente. Cuyo problema reside, sustancialmente, en el absurdo de considerar como «jurídico» un poder que presenta una absoluta libertad en cuanto al fin y que, consiguientemente, se ejerce en ausencia de normas que lo puedan regular tanto sustantiva como procedimentalmente; un poder, además, que actúa antes de que se establezcan las normas constitucionales, en las que reside -según la ortodoxia del positivismo jurídico- la primera y suprema fuente del derecho, que representan el nacimiento del derecho «objetivo». Problema que no se resuelve afirmando el nacimiento coetáneo de Estado y derecho. La cuestión, desde luego, presenta notables dificultades. Una primera es la de que no hay poder si no tiene la capacidad de imponerse (pues de lo contrario no sería poder), por lo que un «poder constituyente», desde este punto de vista, es ya un poder constituido. El poder constituido, a continuación, de por sí no es un poder jurídico o político, lo que hasta el positivismo jurídico admite implícitamente cuando se ve obligado a distinguir entre distintos tipos de poderes. En tercer lugar, no se acierta a saber cómo el poder constituyente pueda vincular a quienes no participan en el proceso de su constitución (menores, no nacidos, etc.). Finalmente, el recurso al pueblo o la nación no sólo no resuelve el problema sino que crea otros y no pequeños ${ }^{9}$. Por donde aparece claramente el quinto bloque de problemas al inicio anunciado: la aporía de si el Estado precede a la Constitución o es producto de la misma ${ }^{10}$.

\section{3. ¿Un Tribunal Constitucional Internacional?}

Si trasladamos lo dicho al ámbito internacional observamos que los problemas y las aporías irresueltas no sólo se mantienen sino que se presentan acrecidos. Eso es lo que sintéticamente vamos a presentar a continuación.

Pues a las evidentes dificultades que conciernen a la organización de un tribunal constitucional internacional han de sumarse las que tocan a la inexistencia de una comunidad política que se dote - ¿por medio de qué poder constituyente?- de una constitución cuya supremacía precisamente el primero vaya a garantizar, sin que se advierta siquiera una común hermenéutica jurídica para la interpretación de la noconstitución.

Asistimos hoy a un proceso de internacionalización y mundialización del constitucionalismo, en buena medida merced un proceso de la misma índole relativo a

${ }^{8}$ CASTELlANO, D. Costituzione e costituzionalismo. Napoli: Edizioni Scientifiche Italiane, 2013, p. 82.

${ }^{9}$ AYUSO, M. (Ed.). El problema del poder constituyente. Constitución, soberanía y representación en la época de las transiciones. Madrid: Marcial Pons, 2012, p. 153.

10 AYUSO, M. EI Estado en su laberinto. Las transformaciones de la política contemporánea. Barcelona: Scire, 2011, p. 31-58. 
los derechos humanos. Fenómenos perfectamente diferenciables, si bien presentan algún nexo entre sí.

La internacionalización de los derechos humanos completó el proceso de su anterior constitucionalización, abriendo los ordenamientos al derecho internacional según la última fase del pensamiento de Kelsen. Pero «la internacionalización del problema no representa su solución», de manera que «la globalización del iuspositivismo no puede ser su misma justificación» ${ }^{11}$. Las modernas Declaraciones internacionales y supranacionales se superponen hoy a las Constituciones, que a su vez prevén esta agregación, creando en ocasiones dificultades de articulación. Debe subrayarse, en este punto, que la idea de unos derechos del género humano, que no es nueva, reviste en nuestros tiempos rasgos peculiares. Las nociones de género humano y de dignidad de la humanidad, lejos de ser universales como en la doctrina cristiana, en la nueva era se convierten en cosmopolitas: «Se cifran en la idea de ciudadano del mundo, que supera las fronteras de un locus geográfico (desterritorialización) y de una polis definida (extra-estatalidad), subordinándose al cosmos, a la manera tendencial de una polis única y de una politeia global» ${ }^{12}$. En fin, el modelo contemporáneo de la protección de los derechos humanos, sin romper con la noción racionalista de la dignidad del hombre ${ }^{13}$, considerado en su individualidad, la sitúa en el ámbito de un concepto no sólo más extenso (el de humanidad) sino incluso más abstracto, ya que la abstrae de la sociabilidad natural de los hombres (que viven en una estructura de relación con otros individuos y diversos cuerpos sociales), de la forma histórica de las asociaciones humanas (incluidas las naciones), de la actualidad de las generaciones humanas (pues refiere también los derechos tutelables a las generaciones futuras), del territorio nacional (rectius de las fronteras estatales) y aun del propio Estado ${ }^{14}$. Una consecuencia inevitable de ese paradójico cosmopolitismo abstracto y no universal va a ser la fragmentación que a no mucho tardar hemos de experimentar.

En cuanto a la internacionalización del derecho constitucional a través de un tribunal constitucional, no debiera olvidarse el acervo existente a propósito del derecho internacional público, pero tampoco las aporías antes mentadas e irresueltas. En cuanto a lo primer, en efecto, el derecho internacional público es derecho sólo en la medida en que, para resolver los conflictos que forman su materia, puede intervenir algún tribunal internacional. Lo que ocurre es que a pesar de llamarse público, se nos presenta -en cuanto depende de la autonomía particular de los Estados- como no menos privado que el derecho de un contrato de sociedad, de manera que tan sólo sería posible en tanto «las repúblicas contratantes se hallasen integradas en una comunidad moral que les impusiera no sólo unos límites formales de procedimiento, sino también un cierto contenido de principios morales necesarios». En esta medida, una sociedad internacional de relaciones privadas podría convertirse en una comunidad de situaciones públicas similar a la del contrato matrimonial, que también presupone una comunidad moral. Hoy, sin embargo, «esta comunidad moral no existe realmente, pues la antigua Comunidad Cristiana fue disuelta por un proceso desintegrador de varios siglos, y ha quedado reducida a unos principios insuficientes para constituir una verdadera comunidad: la Paz y la Economía» ${ }^{15}$.

\footnotetext{
11 CASTELLANO, D. Razionalismo e diritti umani. Sull'antifilosofia politico-giuridica della «modernità». Torino: Giapicchelli, 2003, p. 97.

${ }_{12}$ DIP, R. M. Los derechos humanos y el derecho natural. De cómo el hombre imago Dei se tornó imago hominis. Madrid: Marcial Pons, 2009, p. 107.

${ }^{13}$ ORS, A. d', La llamada «dignidad humana». La Ley, v. XLV, n. 148, p. 1-4, 1980.

${ }^{14}$ DIP, R. M. op. cit., pág. 110. También aquí debemos a Álvaro d'Ors notables reflexiones. Puede verse, sobre todo, su Bien común y enemigo público. Madrid: Marcial Pons, 2002.

${ }^{15}$ ORS, A. d'. Una introducción al estudio del derecho. $8^{\text {a }}$ ed. Madrid: Rialp, 1989, p. 150.
} 


\section{Coda}

La experiencia, en un radio menor, de la Constitución europea, varada tras el fracaso del Tratado constitucional, por más que haya seguido adelante a trancas y barrancas tras el Tratado de Lisboa, puede servir para hacer visibles no sólo las mil y una dificultades del proceso, pues las dificultades están para ser superadas, sino las mil y una debilidades que se hallan en su base.

El constitucionalismo, con su dimensión constructivista de raíz utópica ${ }^{16}$, se encuentra en horas bajas. Tanto que se ha querido sustituirlo por un «neoconstitucionalismo». En su seno encontramos mimbres entrelazados de un constitucionalismo radicalizado, otro decadente y otro finalmente reactivo. De aquí que quizá fuera preferible denominarlo «post-constitucionalismo». Y de ahí también que si hoy se duda de la capacidad del constitucionalismo para resolver los problemas del tiempo, quizá no sea buena la idea de expandirlo ${ }^{17}$.

\section{Referencias}

AYUSO, M. La costituzione fra neo-costituzionalismo e post-costituzionalismo. In: CASTELLANO, D. (Ed.). La Facoltà di Giurisprudenza dell'Università di Udine, Dieci anni. Udine: 2009, p. 63-76.

AYUSO, M. El Estado en su laberinto. Las transformaciones de la política contemporánea. Barcelona: Scire, 2011, p. 31-58.

AYUSO, M. (Ed.). El problema del poder constituyente. Constitución, soberanía y representación en la época de las transiciones. Madrid: Marcial Pons, 2012, p. 153.

CASTELLANO, D. Razionalismo e diritti umani. Sull'antifilosofia politicogiuridica della «modernità». Torino: Giapicchelli, 2003, p. 97.

CASTELLANO, D. La naturaleza de la política. Barcelona: Scire, 2006, p. 11-18.

CASTELLANO, D. Costituzione e costituzionalismo. Napoli: Edizioni Scientifiche Italiane, 2013, capítulo IV.

CUNHA, P. F. da. Costituição, direito e utopia. Coimbra: Coimbra Editora, 1996.

DIP, R. M. Los derechos humanos y el derecho natural. De cómo el hombre imago

Dei se tornó imago hominis. Madrid: Marcial Pons, 2009, p. 107.

FAVOREU, L. Les cours constitutionelles. Paris: PUF, 1986.

FERRARA, C. A. Las «uniones del mismo sexo» y el problema del positivismo legal. Una perspectiva desde los Estados Unidos. In: AYUSO, M. (Ed.). Estado, ley y conciencia, Madrid: Marcial Pons, 2010, p. 89-127.

${ }^{16}$ CUNHA, P. F. da. Costituição, direito e utopia. Coimbra: Coimbra Editora, 1996.

17 AYUSO, M. La costituzione fra neo-costituzionalismo e post-costituzionalismo. In: CASTELLANO,

D. (Ed.). La Facoltà di Giurisprudenza dell'Università di Udine, Dieci anni. Udine: 2009, p. 63-76. 
GENTILE, F. Ordinamento giuridico fra virtualità e realtà. $3^{\text {a }}$ ed. Padova: CEDAM, 2005.

HÄBERLE, P. (Hgrs.), Verfassungsgerichtsbarkeit. Darmstadt: Wissenschaftliche Buchgesellschaft, 1976.

MCILWAIN, Charles H. Constitutionalism. Ancient and modern. Revised edition, Ithaca: Cornell University Press, 1947.

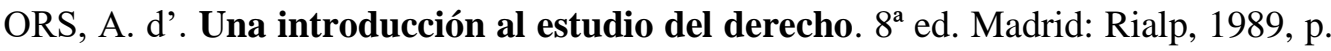
150.

ORS, A. d’. La llamada «dignidad humana». La Ley, v. XLV, n. 148, p. 1-4, 1980.

ORS, A. d'. Bien común y enemigo público. Madrid: Marcial Pons, 2002.

PEREIRA MENAUT, A.C. Rule of law o Estado de derecho. Madrid: Marcial Pons, 2003. 